\title{
Avaliação da agradabilidade facial de pacientes portadores de padrão facial II e III por ortodontistas e leigos
}

\section{Assessment of facial attractiveness of patients with facial pattern II and III for orthodontists and lay people}

\author{
RESUMO \\ Objetivo: comparar a avaliação de ortodontistas e leigos quanto a \\ agradabilidade facial de indivíduos portadores de Padrão II e III.
}

Metodologia: trinta ortodontistas e 30 leigos julgaram fotos do perfil facial de 64 indivíduos Padrão II e III (34 Padrão II e 30 Padrão III), mediante marcação de uma escala subjetiva (VAS) de $10 \mathrm{~cm}$.

Resultados: após a obtenção das avaliações os resultados foram submetidos à análise estatística (teste de Mann- Whitney), que demonstraram que os grupos de avaliadores ortodontistas e leigos divergiram nas suas avaliações, sendo estas diferenças estatisticas significantes.

Conclusões: os leigos foram mais rigorosos do que os ortodontistas, considerando as faces da amostra menos agradáveis, e ambos consideraram os indivíduos de Padrão III do gênero feminino como os mais agradáveis.

Palavras-chave: Face; Estética; Má Oclusão.

\begin{abstract}
Aim: compare the evaluation of orthodontics and lay people on facial attractiveness of pattern II and III subjects.

Methodology: thirty orthodontists and 30 laymen judged a profile facial photos of 64 subjects standard II and III (34 standard II e 30 standard III), making as visual analogical scale (VAS) with $10 \mathrm{~cm}$.
\end{abstract}

Results: after evaluation, the results were submitted to a statistics analysis (Mann- Whitney test) showed that the groups of evaluators orthodontists and lay people differed in their assessments, and these differences are statistically significant.

Conclusions: the laymen was more rigorous than orthodontics, and both considered the female pattern III more agradable.

Keywords: Face; Esthetics; Malocclusion.
Júlio César Cavichiolo*

Marcio Salazar**

Osmar Aparecido Cuoghi***

Marcos Rogério de Mendonça***

Laurindo Zanco Furquim****

* Especialista em Ortodontia (UEM)

** Doutorando em Ortodontia (Unesp

- Araçatuba)

*** Professor do Departamento de Ortodontia (Unesp - Araçatuba SP)

**** Professor do Departamento de Ortodontia (UEM - Maringá PR)

Endereço para correspondência:

Júlio César Cavichiolo

Av. Brasília, 4889

Novo Mundo, Curitiba - Pr

Cep: $81020-010$

(41) 3246- 2982.

julio_orto@hotmail.com

Enviado: 10/7/2009.

Aceito: 10/12/2009. 


\section{INTRODUÇÃO}

A preocupação com a beleza facial acompanha o desenvolvimento das civilizações. Na Ortodontia não é diferente e desde Angle, a estética facial já era considerada indispensável para a definição do diagnóstico correto, elaboração do planejamento e o sucesso no tratamento ortodôntico. Ao utilizar a avaliação subjetiva para eleger faces representativas do ideal de beleza, como a de Apolo Belvedere, este autor tentava estabelecer parâmetros de normalidade a serem conquistados com o tratamento ortodôntico ${ }^{1}$.

O advento da cefalometria desviou a atenção da face para a posição do esqueleto e dos dentes, permitindo o estabelecimento de referências de normalidade mensuráveis. Iniciou-se um período de grande paradoxo entre os objetivos dos ortodontistas e de seus pacientes. Enquanto os pacientes desejavam melhorar sua aparência, os ortodontistas baseavam-se principalmente nos desvios das relações físicas/matemáticas/numéricas/ normativas entre dentição, esqueleto e tecido mole.

A posição do incisivo inferior, avaliada na telerradiografia do perfil, passou então a definir a necessidade de exodontias a fim de obter um ângulo entre o longo eixo do incisivo inferior e o plano mandibular (IMPA) de $90^{\circ} \pm 5^{\circ}$. Segundo Tweed, esse parâmetro estava relacionado à estética facial agradável. A utilização deste e de outros parâmetros cefalométricos na definição dos planos de tratamentos resultou em extrações desnecessárias e iatrogênicas para a estética facial, identificadas por autores da literatura norte-americana como dish face ou face côncava ${ }^{2}$.

Devido à limitação da análise numérica do perfil facial, foram sugeridas análises subjetivas que caracterizassem o perfil facial. Mais intensamente, no final dos anos 60, os ortodontistas começaram a valorizar o papel dos fatores subjetivos como diagnóstico principal no planejamento, facilitando o entendimento de cada estrutura da face e seu relacionamento com as demais, permitindo a verificação do seu grau de beleza assim como a auto-avaliação do paciente ${ }^{3-6}$.

Para que se pudesse classificar a face como bela, estimativas do que seria considerado belo ou não deveriam ser registradas, mas existem algumas divergências no que diz respeito a quem deveria realizar tal classificação, se pessoas leigas ou profissionais ${ }^{7}$. Uma das possíveis vantagens da classificação realizada por leigos seria a ausência de opiniões formadas a respeito da beleza dos perfis, visto que não receberam treinamento ortodôntico, portanto, estariam aptos a escolher as faces mais belas somente por sua agradabilidade. Os profissionais, por sua vez, com o treinamento recebido durante seus anos de estudo e prática clínica, poderiam classificar as faces com melhor constância, visto que estariam menos sujeitos às influências externas (mídias impressa e visual).

O uso da classificação do Padrão, proposta por Capelozza Filho ${ }^{8}$ (2004) tem o Padrão I identificado pela normalidade facial. A má oclusão 
quando presente é apenas dental não associada a qualquer discrepância esquelética sagital ou vertical. Os pacientes portadores dos Padrões II e III apresentam discrepância sagital entre a maxila e a mandíbula identificada, principalmente, na avaliação lateral da face. Indivíduos classificados como Padrão I na visão frontal e II ou III no perfil apresentam melhor prognóstico que aqueles Padrões II ou III nas vistas frontal e lateral, nos quais o desequilíbrio é grave o suficiente para ser identificado na avaliação de frente devido às suas conseqüências verticais.

A análise facial foi baseada como um método de independência dos antigos conceitos cefalométricos puros, para utilizar uma análise mais condizente com a necessidade estética dos pacientes. Foi proposto um novo diagnóstico, com base na análise morfológica da face, a qual se baseia não na "segurança" dos números, mas sim na análise da fotografia de frente e perfil do paciente ${ }^{8}$. Classificou as faces como: Padrão I, Padrão II, Padrão III, Padrão face curta e Padrão face longa ${ }^{8}$.

Embora o Padrão seja constante, detalhes da manutenção variam nas diferentes doenças, porém, sempre obedecendo ao comando genético, que, em essência, define o Padrão craniofacial.

O conceito de que a determinante genética expressa na morfologia tegumentar da face condiciona de maneira primária todos seus componentes, incluindo dentes. Uma vez definida a morfologia facial, permite-se o diagnóstico do Padrão e um efeito cascata de tendências.

O referencial estético deve ser um conjunto de características que permite o equilíbrio facial e não uma forma escolhida por algum critério. Assim, o objetivo desta pesquisa é verificar se existe diferença estatisticamente significante de agradabilidade facial entre os Padrões II e III, quanto às notas atribuídas pelos avaliadores.

\section{MATERIAL E MÉTODOS}

Este trabalho foi submetido e aprovado pelo comitê de ética da Universidade Estadual de Maringá.

Para a seleção da amostra foram avaliadas as fotografias do perfil facial de 74 indivíduos brasileiros. Os indivíduos foram previamente classificados por três examinadores calibrados, de acordo com as características dos Padrões descritas por Capellozza Filho ${ }^{8}$ (2004).

Os critérios utilizados para a inclusão do indivíduo na amostra foram: 1) que o paciente Padrão II ou III deveria receber a mesma classificação dos três examinadores; 2) não ter sido submetido previamente a tratamento ortodôntico ou cirurgia plástica facial. Após estes critérios, a amostra foi constituída de 64 indivíduos (34 Padrão II e 30 Padrão III). Dos indivíduos Padrão II: 18 indivíduos femininos (Fig. 1) e 16 indivíduos masculinos (Fig. 2) e do Padrão III: 15 indivíduos femininos (Fig. 
3) e 15 indivíduos masculinos (Fig. 4). Os critérios de exclusão foram: os portadores de discrepâncias verticais, Padrões face longa e curta e aqueles que são favorecidos pela normalidade das relações esqueléticas sagitais e verticais reconhecidos como Padrão I.

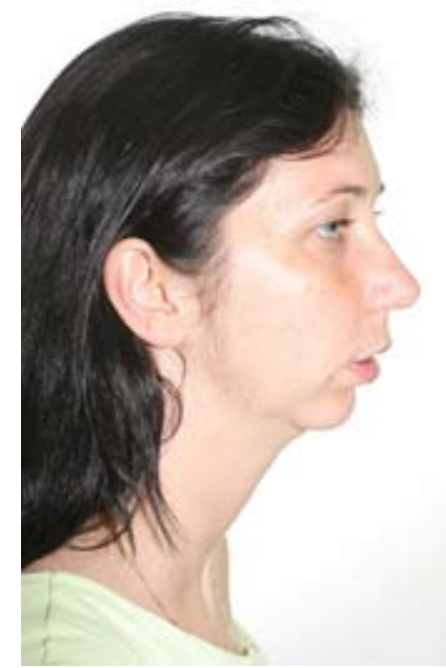

Figura 1. Indivíduo n. 60 da amostra (Padrão II feminino)

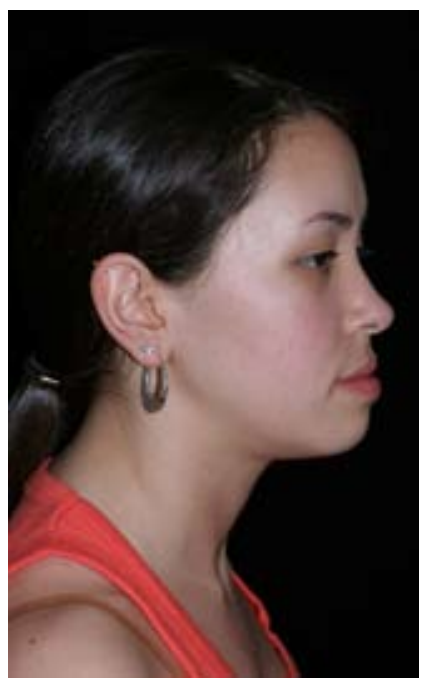

Figura 3. Indivíduo n.56 da amostra (Padrão III feminino)

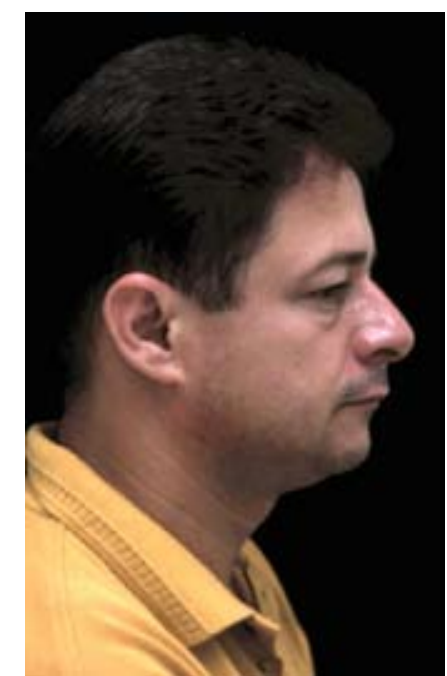

Figura 2. Indivíduo n.19 da amostra (Padrão II masculino)

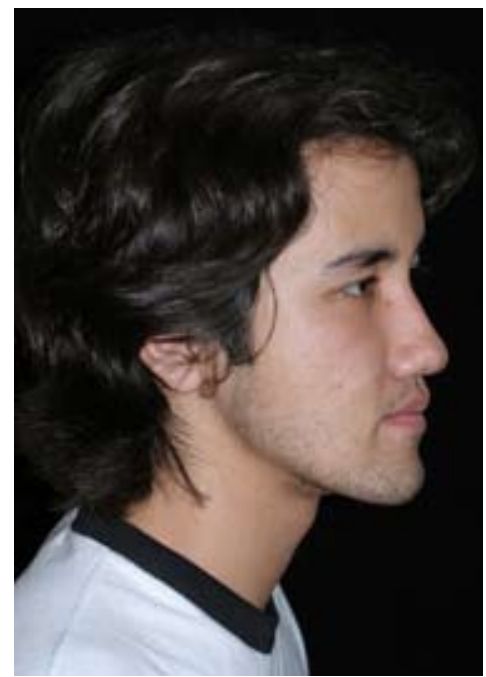

Figura 4. Indivíduo n. 59 da amostra (Padrão III masculino)

O grupo de avaliadores (para classificar a agradabilidade da amostra) foi composta por 30 ortodontistas (especialistas, 18 homens e $12 \mathrm{mu}$ lheres) e 30 leigos (16 homens e 14 mulheres). O grupo de avaliadores tanto os ortodontistas quanto os leigos foram heterogêneos, com o objetivo de reduzir influências individuais, devido ao fato de os indivíduos apresentarem diferentes conceitos estéticos decorrentes de sua formação profissional, individual e social. 
Os avaliadores receberam um álbum contendo todas as fotografias do perfil facial, dispostas de maneira que apenas uma fotografia ficasse disponível em cada avaliação. As fotografias dos Padrões II e III, assim como, do sexo feminino e masculino foram distribuídas de forma aleatória por meio de sorteio com o objetivo de reduzir a tendenciosidade na avaliação. A análise consecutiva das faces do mesmo padrão e sexo favorece a avaliação comparativa dos perfis. A distribuição aleatória das fotos procurou romper o padrão de comparação, na medida em que uma seqüência de imagens de perfis do mesmo Padrão e sexo fosse interrompida por um perfil de Padrão e sexo diferente. Foi solicitado aos examinadores que classificassem cada fotografia em um tempo máximo de 30 segundos, de acordo com a sua opinião, e dessem notas de acordo com o grau de agradabilidade facial segundo a escala (VAS) de 10cm (Fig. 5).

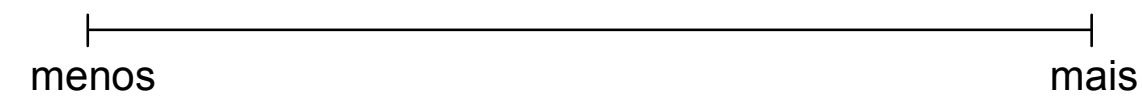

agradável agradável

Figura 5. Escala VAS.

Com o objetivo de avaliar a concordância intra-examinador na avaliação de agradabilidade do perfil, foi selecionado aleatoriamente sete ortodontistas e sete leigos e solicitado aos examinadores que repetissem a classificação estética, com, no mínimo, uma semana de intervalo entre as duas avaliações.

O erro do método foi aplicada para a concordância entre os examinadores (teste de Wilcoxon) verificando que tantos os leigos como os ortodontistas foram consistentes nas suas avaliações. $O$ valor do teste foi superior a 5\% ( $>0,05)$. Pode-se concluir que não houve diferença estatisticamente significante entre as duas medições, de tal maneira, que os avaliadores tenderam a ser consistentes em suas avaliações (Tab. 1)

Tabela 1. Média e desvio-padrão das análises dos leigos e ortodontistas, com base em uma amostra, para a verificação da consistência dos avaliadores.

\begin{tabular}{|c|c|c|c|c|c|}
\hline \multirow[b]{2}{*}{ Avaliador } & \multicolumn{2}{|c|}{$1^{\underline{a}}$ avaliação } & \multicolumn{2}{|c|}{$2^{\underline{a}}$ avaliação } & \multirow[b]{2}{*}{$\mathrm{P}$} \\
\hline & Média & $\begin{array}{l}\text { Desvio- } \\
\text { Padrão }\end{array}$ & Média & Desvio-Padrão & \\
\hline Leigos & 3,90 & 1,97 & 3,86 & 1,92 & 0,6825 \\
\hline Ortodontistas & 4,19 & 2.26 & 4,37 & 2,69 & 0,4157 \\
\hline
\end{tabular}




\section{RESULTADOS}

Na tabela 2 são apresentados os valores médios e desvios padrões das variáveis da analise facial subjetiva do perfil para a amostra estudada. As comparações foram feitas para o Padrão II (indivíduos masculinos e femininos), Padrão III (indivíduos masculinos e femininos) e para a junção dos dois anteriores, que por questões de nomenclatura, aqui serão chamados de Padrão II + III.

Os dados revelam que para os 3 grupos, ortodontistas e leigos divergem nas suas avaliações, pois existiram diferenças estatisticamente significante. Na avaliação dos ortodontistas, os indivíduos Padrão II, III e união de Padrão II e III obtiveram médias de 4,29, 4,33 e 4,31 respectivamente. Já para os leigos, os indivíduos de Padrão II, III e união de Padrão II e III obtiveram médias de 3,67, 3,90 e 3,77 respectivamente (Tab. 2).

Tabela 2. Média e desvio padrão das análises dos leigos e ortodontistas para indivíduos Padrão II e Padrão III e Padrão II + III.

\begin{tabular}{ccc|ccc}
\hline \multirow{2}{*}{ Tipo Facial } & \multicolumn{2}{c|}{ Ortodontistas } & \multicolumn{2}{c}{ Leigos } & \multirow{2}{*}{$P$} \\
\cline { 2 - 5 } & Média & Desvio-Padrão & Média & $\begin{array}{c}\text { Desvio- } \\
\text { Padrão }\end{array}$ & \\
\hline * Padrão II & 4,29 & 2,28 & 3,67 & 2,31 & $<0,0005$ \\
* Padrão III & 4,33 & 2,03 & 3,90 & 2,25 & 0,0004 \\
* Padrão II +III & 4,31 & 2,18 & 3,77 & 2,84 & $<0,0005$ \\
\hline
\end{tabular}

P - valor para o Teste de Mann- Whitney,

* Denota diferença estatística.

Na tabela 3 são apresentados os valores médios, além dos desvios padrões das variáveis da analise facial subjetiva do perfil da amostra estudada. Considere os avaliadores leigos e ortodontistas, e a divisão para os grupos por eles avaliados dadas da seguinte maneira: Padrão II (masculino), Padrão II (feminino), Padrão III (masculino) e Padrão III (feminino).

Verifica-se que na avaliação dos ortodontistas que os indivíduos Padrão III femininos diferiram estatisticamente de todos os demais grupos. As outras combinações de grupos não apresentaram diferença estatisticamente significante para a agradabilidade facial. Para os ortodontistas, os indivíduos dos mais agradáveis para os menos agradáveis foram os de Padrão III feminino com média de 4,57, Padrão II masculino com média de 4,40, Padrão II feminino com média de 4,20 e Padrão III masculino com média de 3,73 (Tab. 3).

$\mathrm{Na}$ avaliação dos leigos, os indivíduos Padrão III femininos também diferiram estatisticamente de todos os demais grupos. As outras combina- 
ções de grupos não apresentaram diferenças estatisticamente significante para a agradabilidade facial. Os indivíduos dos mais agradáveis aos menos agradáveis para os leigos foram os Padrão III femininos com média 4,32, Padrão II masculino com média de 3,71, Padrão II feminino com média 3,64 e Padrão III masculino com média (Tab. 3).

Tabela 3. Média e desvio-padrão para indivíduos Padrão II e III de ambos os sexos.

\begin{tabular}{llclc}
\hline & Padrão Facial & Média & Desvio Padrão & P \\
\hline \multirow{3}{*}{ Ortodontistas } & II Masculino & 4,40 & 2,23 & \\
& III Masculino & 3,73 & 1,79 & \\
& II Feminino & 4,20 & 2,31 & 0,001420 \\
& *III Feminino & 4,57 & 2,08 & \\
& II Masculino & 3,71 & 2,29 & \\
Leigos & III Masculino & 3,46 & 2,20 & \\
& II Feminino & 3,64 & 2,33 & $<0,0005$ \\
\hline
\end{tabular}

$P$ - Valor para o teste de Kruskal-Wallis.

* Denota diferença estatística.

\section{DISCUSSÃO}

O equilíbrio da face e do sorriso é a busca incessante da Ortodontia, no tratamento dos diferentes Padrões. A análise facial subjetiva permite o estudo das avaliações do Padrão Facial para o diagnóstico do tratamento ortodôntico e da estética facial realizada rotineiramente pela sociedade ${ }^{9}$. As linhas faciais harmoniosas compreendem um dos principais objetivos do tratamento ortodôntico, por isso a análise morfológica da face é o principal recurso diagnóstico para determinação do Padrão Facial que, por sua vez, remete a protocolos de tratamento, prognósticos específicos em diferentes faixas etárias e facilita a comunicação entre o paciente e os profissionais envolvidos no tratamento ${ }^{10}$.

No presente estudo o grau de concordância da agradabilidade facial dos indivíduos Padrão II e III quando avaliados por leigos e ortodontistas, foi realizado para verificar se existiam diferenças estatisticamente significantes.

Para os ortodontistas, as médias das notas nas avaliações foram superiores as notas dadas pelos leigos, ou seja, os ortodontistas consideraram as faces de perfil dos indivíduos da amostra mais agradáveis que os leigos. Esse resultado diverge de outro estudo onde verificaram que os ortodontistas foram mais criteriosos e severos em suas avaliações que os leigos ${ }^{11}$.

A classificação da estética facial torna próximos os ortodontistas, de profissionais de outras especialidades e da expectativa do paciente, além 
de oferecer parâmetros morfológicos importantes para decisões diagnósticas, muitas vezes duvidosas ${ }^{12}$.

Para as comparações realizadas entre Padrão e dimorfismo sexual, avaliou-se separadamente os dois tipos de avaliadores ortodontistas e leigos, com o objetivo de verificar se indivíduos de Padrão II masculino, Padrão II feminino, Padrão III masculino e Padrão III feminino diferem estatisticamente entre si.

Na avaliação dos leigos, os indivíduos Padrão III femininos também diferiram estatisticamente de todos os demais grupos. As outras combinações de grupos não apresentaram diferenças estatisticamente significante para a agradabilidade facial. Os indivíduos dos mais agradáveis aos menos agradáveis para os leigos foram os Padrão III femininos com média 4,32, Padrão II masculino com média de 3,71, Padrão II feminino com média 3,64 e Padrão III masculino com média. Na avaliação dos ortodontistas o Padrão III feminino também foi o mais agradável.

Esses resultados divergem de outro trabalho onde observaram que as faces de perfil convexo são mais agradáveis e, especificamente quanto ao Padrão III, as mais agradáveis são do sexo masculino ${ }^{8}$.

O comprimento da linha queixo-pescoço, proporcionalmente à altura do terço inferior da face e um comprimento horizontal do nariz aumentado em relação à altura do nariz, diferem nas faces masculinas e femininas, e com isso as faces são subjetivamente classificadas diferentemente quanto a agradabilidade ${ }^{7}$.

Apesar da literatura existente sobre Padrão Facial, poucos foram os estudos encontrados que relacionassem a análise subjetiva do perfil facial com a agradabilidade, mais estudos devem ser realizados, relacionando-se a agradabilidade facial de diferentes Padrões associados a sexo e diferentes grupos de avaliadores.

\section{CONCLUSÕES}

- há diferenças na avaliação da agradabilidade facial entre leigos e ortodontistas. As opiniões são diferentes, onde o leigo mostrou-se mais rigorosos nas notas atribuídas ao perfil facial;

- na avaliação de agradabilidade entre os Padrões e sexo, verificou-se que os grupos de avaliadores concordaram que o Padrão III feminino foi o mais agradável. Contudo, mais pesquisas com diferentes metodologias precisam ser aplicadas.

\section{REFERÊNCIAS}

1. Angle EH. Treatment of malocclusion of the teeth. Angle's system. 7. ed. Philadelphia: S. S. White; 1907. p. 60-87, 159-160.

2. Holdaway RA. A soft tissue cephalometric analysis and its use in orthodontic treatment planning. Part I. Am J Orthod Dentofacial Orthop 1983; 84(1):1-28. 
3. Arnett GW, Bergman RT. Facial keys to orthodontic diagnosis and treatment planning. Part I. Am J Orthod Dentofacial Orthop 1993; 103(4 a):299-312.

4. Arnett GW, Bergman RT. Facial keys to orthodontic diagnosis and treatment planning. Part II. Am J Orthod Dentofacial Orthop 1993 b; 103(5 b):395-411.

5. Mcnamara JA Jr, Brust EW, Riola ML. Soft tissue evaluation of individuals with an ideal occlusion and a well- balanced face. In: McNamara Jr. JA. Esthetics and treatment of facial form. Center of Human Growth and Development, Craniofacial Growth Series. University Michigan: Ann Arbor; 1993. p. 115-146.

6. Nanda RS, Gosh J. Harmonia entre os tecidos moles da face e do crescimento no tratamento ortodôntico. In: Sadowsky PL. Atualidades em Ortodontia. São Paulo: Premier; 1997. Seção II, p.65-71.

7. Trevisan F, Gil MCTLA. Análise fotogramétrica e subjetiva do perfil facial de indivíduos com oclusão normal. R Dental Press Ortodon Ortop Facial, Maringá 2006; 11(4):24-35.

8. Capelozza Filho L. Diagnóstico em Ortodontia. 1. ed. Maringá: Dental Press; 2004.

9. Suguino R, Ramos AL, Terada HH, Furquim LZ, Maeda L, Silva Filho OG. Análise facial. R Dental Press Ortodon Ortop Facial. Maringá 1996; 1(1):86-107.

10. Bergman RT. Cephalometric soft tissue facial analysis. Am J Orthod Dentofacial 1999; 116(4):373-89.

11. Diogo EL, Bernardes LAA. Estudo comparativo entre as preferências estéticas do perfil facial tegumentar avaliado por ortodontistas e leigos com padrões cefalométricos existentes. R Dental Press Ortodon Ortop Facial 2003; 8(5):49-58.

12. Reis SAB. Análise facial numérica e subjetiva do perfil e análise da relação oclusal sagital de brasileiros, adultos, leucodermas, não tratados ortodonticamente. [Dissertação de Mestrado]. São Bernardo do Campo: Faculdade de Odontologia da Universidade Metodista de São Paulo; 2001. 